Casos Clínicos

Arch. Esp. Urol., 57, $10(67-69), 2005$

\section{METÁSTASIS MAMARIA COMO MANIFESTA- CIÓN INICIAL DE UN CARCINOMA RENAL}

\author{
José Luis Fírvida Pérez, José M iguel Calvo Pestonit, \\ Francisco Martínez de Paz y Mercedes Salgado \\ Fernández.
}

Servicios de O ncología, Ana to mía Pa to lógica ${ }^{1}$ y Cirugía² Complejo Hospitalario de 0 urense. 0 rense.

España

Resumen.- O BJETIVO : Presentación de un caso de metástasis mamaria como primera manifestación de un carcinoma renal.

M ÉTO DO : Paciente varón de 72 años que consultó por tumoración dolorosa en mama derecha. Descripción de la historia clínica, exploraciones complementarias, resultados de la biopsia, y tratamiento posterior.

RESULTADO S: El estudio ana tomopa to lógico confirmó el resultado de metástasis de carcinoma de células claras. Por TAC se confirmó la presencia de un tumor renal bilateral.

CON CLUSIO NES: Las metástasis en mama como presentación de un carcinoma renal son excepcionales. Se realiza una revisión de la literatura al respecto

Palabras clave: M etástasis ma maria. Carcinoma renal. Inmunoterapia.

Summary.- $O$ BJEC TIVES: To report the case of a breast metastasis as initial presentation of renal carcinoma.

METHODS: 72 -year-old male patient who consulted for a painful right breast tumor. W e describe clinical history, complementary tests, biopsy and treatment.

RESULTS: Pathologic study confirmed a metastasis of a renal clear cell carcinoma. A CT scan confirmed the existence of bilateral renal tumors.

José Luis Fírvida Pérez

Servicio de 0 ncología

Complejo Hospitalario de 0 urense

C/ Ramon Puga, 52

320050 rense. (España)

e-mail: jlfirvida@wanadoo.es

Trabajo recibido: 12 de abril 2004
CON CLUSIO N S: Breast metastases are exceptional as initial presentation of a renal carcinoma. W e performed a bibliographic review on the topic.

Keyw ords: Breast metastasis. Renal carcinoma. Immunotherapy.

\section{INTRODUCCIÓN}

El carcinoma de células renales (CCR) constituye el 3\% del total de tumores y el $90 \%$ de los tumores malignos del riñón. Tiene una incidencia del $2.5 \%$ de las neoplasias malignas en el varón y del $1.6 \%$ en la mujer.(1)

Un tercio de los pacientes se presentan con metástasis al diagnóstico, siendo las localizaciones más frecuentes pulmón, ganglios linfáticos y hueso, seguidos de hígado, piel y cerebro.(2)

La afectación mamaria metastásica es rara, estando recogidos en la literatura alrededor de 300 casos, siendo excepcional su presentación como primera manifestación de la enfermedad.(3-5)

Aportamos un caso de CCR que debuta como tumoración metastásica mamaria como presentación inicial de la enfermedad.

\section{CASO CÚNICO}

Paciente varón de 72 años de edad, con antecedentes de desprendimiento de retina en ojo derecho hacía 6 años, y diabetes tipo II controlada con dieta. Consulta en el Servicio de Cirugía por dolor en mama izquierda de 3 meses de evolución, sin otra sintomatología acompañante.

A la exploración física se objetiva una tumoración en cuadrante súperointerno de mama izquierda, de $5 \mathrm{cms}$ de diámetro, sólida, firme y adherida a planos profundos. No se palpan adenopatías axilares, supraclaviculares ni en otros territorios.

Se practicó una analítica general, con hemograma y bioquímica que resultan normales. Marcadores tumorales CEA y CA 15.3 dentro de la normalidad. La Rx de tórax no mostró alteraciones.

Se realizó una punción aspirativa con aguja fina (PAAF) de la tumoración, que resultó inconclusiva. Finalmente, se practica, mediante incisión arqueada intraareolar, una biopsia con extirpación completa de la lesión.

El estudio macroscópico de la pieza mostró un fragmento de tejido de $6 \times 4 \mathrm{cms}$ de bordes irregulares. Al corte está constituído fundamentalmente por tejido de aspecto sólido de color pardo, consistencia elástica y carácter deleznable. El examen microscópico objetivó infiltración del tejido graso de la región mamaria izquierda por una neoplasia de estirpe epitelial, constituída por células de amplio citoplasma claro, que crecen formando amplios cordones separados por escaso estroma vascular. Las células mostraban núcleos con 


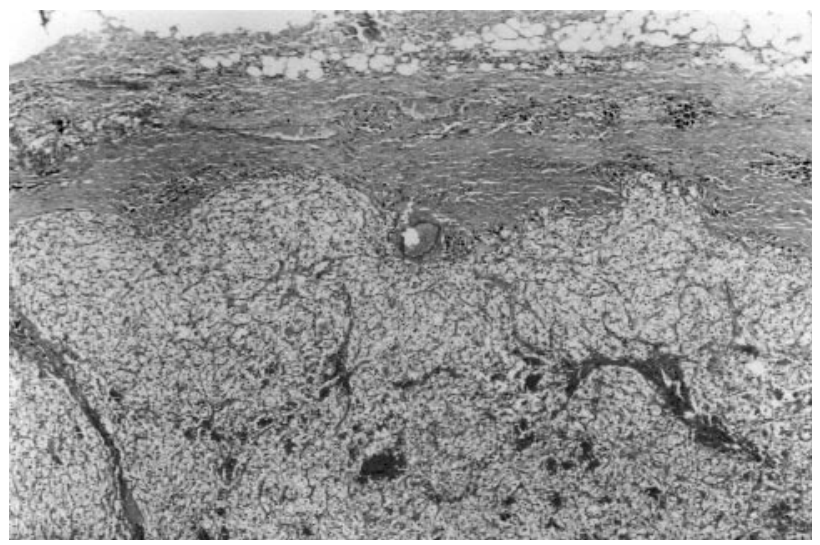

FIG URA 1: Estudio ana tomopatológico (H-E): Carcinoma de células claras

moderado pleomorfismo, nucleolos pequeños y ocasionales figuras de mitosis. El estudio anatomopatológico definitivo fue de carcinoma de células claras metastático, con tumor primario presumiblemente de origen renal (Figura 1).

Ante los hallazgos histológicos, se solicitó un TAC tóracoabdómino-pélvico que confirmó la presencia de un tumor renal bilateral (Figura 2). En el riñón izquierdo se objetivó una masa tumoral hipervascularizada con necrosis central, de $12 \times 7$ cms, ocupando su polo medio-inferior; en el riñón derecho existía otra tumoración en su polo inferior; se asociaba trombosis de la vena renal izquierda (Figura 3), y adenopatías retroperitonea les e ilíacas externas bilaterales.

Descartada la cirugía por afectación renal bilateral y extensión ganglionar, se derivó al paciente al Servicio de O ncología, iniciando tratamiento inmunoterápico con Interleukina-2 durante 6 meses con estabilización de su enfermedad tumoral, aunque con mala tolerancia (astenia intensa, anorexia, artralgias, febrícula) quedando en controles periódicos. Al año del diagnóstico inicial, presentó por TAC progresión de la enfermedad local y metástasis pulmonares bilaterales, optando por un tratamiento de manteni-

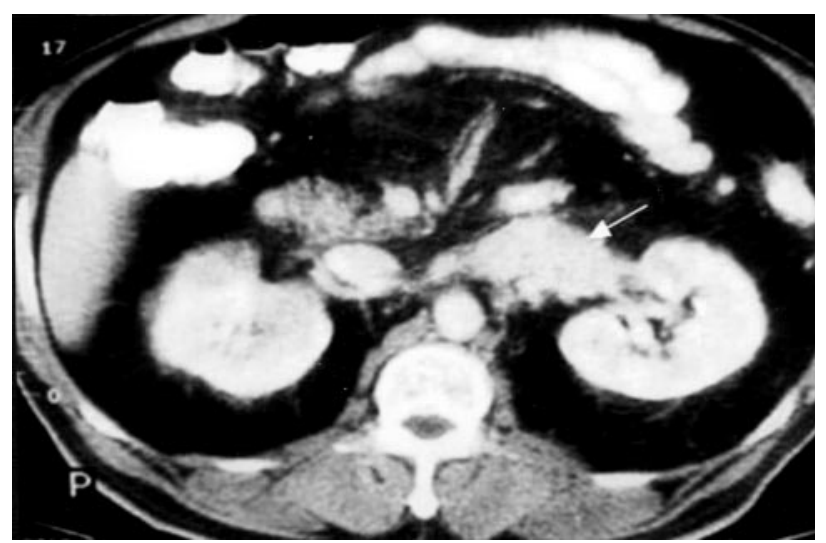

FIG URA 3: TAC: Trombosis de la vena renal izquierda (flecha).

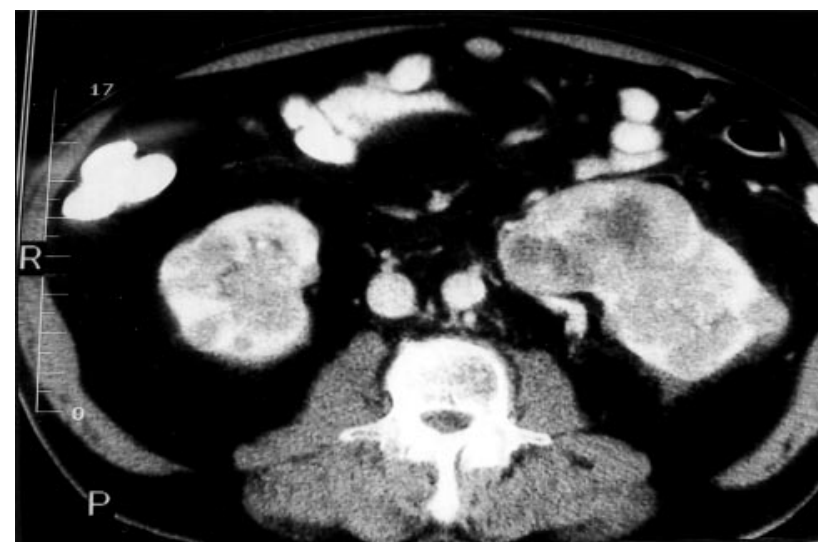

FIG URA 2: TAC: Tumor renal bilateral.

miento con dosis bajas de interferón, tratamiento que mantiene en la actualidad a los 2 años del diagnóstico.

\section{DISCUSIÓN}

Existen recogidos en la literatura alrededor de 300 casos de metástasis mamarias, la mayoría reflejados como casos aislados o pequeñas series (5). La incidencia de metástasis en la mama es del 1,2-2\% en series clínicas y del 1,7-6,6\% en series a utópsicas. La razón cáncer primario/ cáncer metastático en mama se sitúa en 165:1.

Excluídas las neoplasias hema tológicas, los tumores que con más frecuencia presentan metástasis mamarias en la mujer son el cáncer de la mama contralateral, y en el varón, el cáncer de próstata ; le siguen, en orden de frecuencia el cáncer de pulmón y el melanoma; ocasionalmente, se han descrito en cáncer de estómago, colorrectal, faringe, páncreas, ovario, cérvix, útero, riñón, tumor carcinoide y rabdomiosarcomas. (3-10)

Se objetivan adenopatías axilares en el 14-42\% de los casos, y la afectación mamaria bilateral ocurre en el 8-26\%. En el estudio mamográfico, la metástasis mamaria se suele comportar como una masa solitaria y circunscrita, de márgenes finos, irregulares y definidos, sin presencia de microcalcificaciones ni infiltración cutánea (a diferencia del cáncer primario de mama)(5) El diagnóstico definitivo es histopatológico; la presencia de células claras orientará a tumor renal; un hallazgo de adenocarcinoma productor de mucina, a cáncer de estómago o intestinal; finalmente, los hallazgos inmunohistoquímicos pueden ser de gran utilidad en algunos casos (por ejemplo, positividad para proteína S-100 y HMB-45 en melanomas). (3)

Habitualmente, la aparición de metástasis mamarias ocurre en el curso de la evolución natural de la neoplasia maligna, coincidiendo con la presencia de metástasis en otras localizaciones. Según las series, las metástasis mama rias serían la primera manifestación en el $8-40 \%$ de los casos. (5) 
En el CCR, la presencia de metástasis en la glándula mamaria es muy infrecuente. Dada su evolución, en ocasiones imprevisible, se han descrito incluso casos aislados de aparición tardía. Así, Carr (7) describe una metástasis mamaria única 5 años después del diagnóstico inicial de carcinoma renal; y en el caso comunicado por Hardy, la metástasis en mama (también única) se detectó 18 años después de la nefrectomía. (8)

Finalmente, el debut de un CCR como metástasis en mama resulta excepcional. Hemos recogido 3 casos $(5,9,10)$ de metástasis mamaria como manifestación inicial de un carcinoma renal, similar al que nosotros reportamos.

El $60 \%$ de los pacientes con CCR presentarán, en algún momento de la evolución de la enfermedad, metástasis a distancia. El carcinoma renal metastático tiene un pronóstico sombrío, con una mediana de supervivencia inferior a un año, y una supervivencia a 3 y 5 años del $4,4 \%$ y $1,7 \%$ respectivamente.(1) Hasta la actualidad, el tratamiento con quimioterapia y hormonoterapia en CCR se considera ineficaz, con tasas de respuestas inferiores al $5 \%$ y de corta duración. Con el desarrollo de la inmunoterapia, especialmente con Interferón alfa e Interleukina-2, en monoterapia o combinación, se obtiene una tasa de respuestas del $15-20 \%$, algunas de ellas de larga duración, por lo que se considera en la actualidad el tratamiento de elección, siendo la vía de investigación que en el futuro puede presentar resultados más favorables.

\section{BIBUOGRAFIA Y LECTURAS \\ RECOMENDADAS (*lectura de interés y \\ **lectura fundamental)}

**1. LINEHAN, W.M.; SHIPLEY, W.U.; PARKINSON, D.R.: "Cancer of the kidney and ureter". En "Cancer: Principles and practice of Oncology" De Vita VT, Hellman S, Rosenberg SA 5th ed. 1271. Lippincott-Raven. Philadelphia 1997.

*2. DEKERNION, J.B.; RAMMING, K.P.; SMITH, R.B.: "The natural history of metastatic renal cell carcinoma: A computer analysis". J. Urol., 120: 148. 1978.

**3. DONEGAN, W.L.; SPRATT, J.S.: "Metastases to the breast from nonmamary cancers". En "Cancer of the breast". Donegan and Spratt 5th ed. 820. Elsevier Science. St Louis (USA) 2002.

**4. HAJDU, S.I.; URBAN, J.A.: "Cancers metastatic to the breast". Cancer, 29: 1691. 1972.

**5. AMICHETTI, M.; PERANI, B.; BOI, S.: "Metastases to the breast from extramammary malignancies". Oncology, 47: 257. 1990.

*6. DI BONITO, L.; LUCHI, M.; GIARELLI, L. y cols.: "Metastatic tumors to the female breast. An autopsy study of 12 cases". Path. Res. Pract., 187: 432. 1991.

*7. CARR, B.I.: "Renal carcinoma manifesting as breast mass". Urology, 21: 166. 1983.

**8. HARDY, S.C.; BENSON, E.A.: "Solitary breast metastasis from a hypernephroma". Eur. J. Surg. Oncol., 13: 365. 1987.

**9. CHICA, G.A.; JOHNSON, D.E.; AYALA, A.G.: "Renal cell carcinoma presenting as breast carcinoma". Urology, 15: 389. 1980.

*10. MASTERS, A.: "Hypernephroma presenting as a lump in the breast". Aust. N.Z. J. Surg., 60: 395. 1990.

\section{Casos C línicos \\ Arch. Esp. Urol., 58, 1 (69-71), 2005 \\ ALTERACION COGNITIVA Y CONDUCTUAL COMO REACCION ADVERSA NO DESCRITA A TAMSULOSINA.}

\author{
N icolás Alberto C ruz Guerra y María Pilar Perales \\ Céspedes. ${ }^{1}$
}

Servicio de Urología. Complejo Hospitalario de Zamora y M.I.R. de Medicina Familiar y Comunitaria ${ }^{1}$. Centro de Salud "Virgen de la Concha". Zona Básica de Salud de Zamora-Capital. Área de Salud de Zamora . Zamora. España

Resumen.- O BJETIVO : Presentación de un caso de reacción adversa a la tamsulosina.

METODO : Describimos el caso de un paciente varón de 80 años al que se instauró tratamiento alfabloqueante tras retención aguda de orina, de cara a realizar un posterior intento de retirada de catéter vesical.

RESULTADO S: El paciente presentó - coincidiendo con las tres únicas administraciones del fármaco ; episodios autolimitados de desorientación témporoespacial y alteración conductual. El tratamiento fue suspendido.

CON CLUSIO NES: Aportamos un caso de efecto adverso a tamsulosina no descrito. Hacemos referencia a los mecanismos de fármacovigilancia. Señalamos la importancia de la coordinación entre niveles asistenciales.

Palabras clave: Tamsulosina. Efectos adversos. Terapia.
$\mathrm{N}$ icolás Alberto C ruz G uerra. Av. de Requejo, nํ 24, portal 1, 100 D. 49003. Zamora. España. e-mail: ncruz_g@hotmail.com Trabajo recibido: 28 de abril 2004 